\title{
ROLE OF INNOVATIONS AND KNOWLEDGE - INFRASTRUCTURE AND INSTITUTIONS
}

\author{
András Nábrádi \\ University of Debrecen, Faculty of Applied Economics and Rural Development \\ 4032 Debrecen Böszörmény út 138.
}

\begin{abstract}
There is a well known saying: Research converts money into knowledge, innovation converts knowledge into money.
The knowledge-based economy has four pillars: innovation, education, the economic and institutional regime, and information infrastructure. Transformation towards a knowledge-based economy will necessarily shift the proportion and growth of national income derived from knowledge-based industries, the percentage of the workforce employed in knowledge-based jobs and the ratio of firms using technology to innovate. Progress towards a knowledge-based economy will be driven by four elements: human capital development, knowledge generation and exploitation (R\&D), knowledge infrastructure. Increased investment in these four areas will certainly have an impact. National experience, however, suggests that an incremental approach will not work. Nations that have achieved accelerated growth in outputs and capabilities have acted decisively, targeting investments in areas of strategic opportunity. The organizational and infrastructural improvement of research requires supranational cooperation and the promotion of the free movement of knowledge. Therefore, the EU decision on the establishment of the European Institute of Innovation and Technology (EIT), which ensures that the GDP proportion for research and development (R\&D) shall achieve 3\% stipulated by member states in the long run, is particularly welcome.
\end{abstract}

Key words: Innovation, knowledge, infrastructure, institutions

\section{Introduction}

The concept of innovation has been interpreted in several ways. Its generally accepted definition by the World Bank is the following: the use of new ideas, new technologies or new ways of doing things in a place or by people where they have not been used before.

A related saying from the last century states that research converts money into knowledge - i.e. a body of knowledge, and innovation converts knowledge into money again. Figure 1. presents the structure of traditional innovation models.

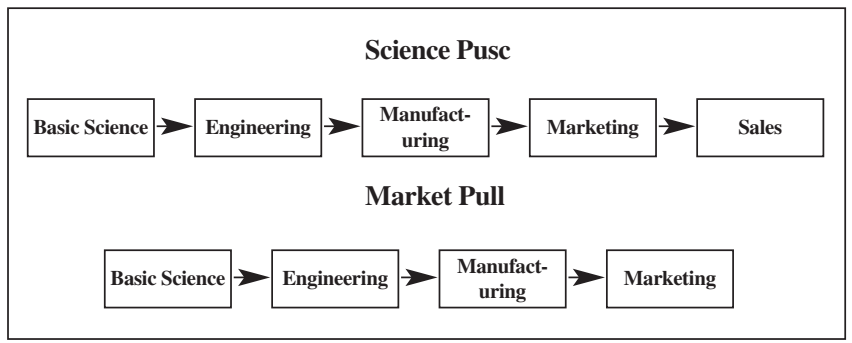

Figure 1. Traditional models of innovation

The first step of knowledge-generated innovation is basic research, which is manifested, through applied research activities and engineering design, in concrete products or services. Marketing tools can support the distribution of these concrete products or services for the general public, thus new products and services are passed on to the end user.
The traditional innovation model has a marketinginduced variant as well. In this case, improvement is generated by market demands and new products reach consumers after the production process.

In the 90s, the above mentioned characteristic separation of innovation models was replaced by the so-called coupling model of innovation which came into the limelight. The concept of this model is that research from beneath and market demand from above exert a simultaneous effect on the realization of new products and services. This is illustrated by Figure 2 .

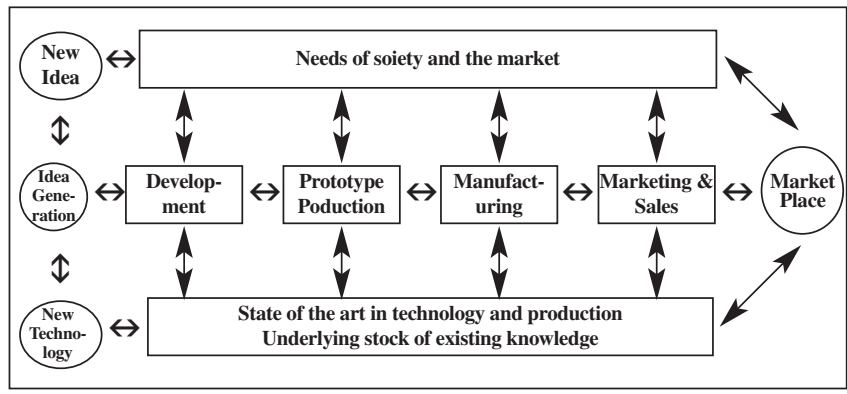

Figure 2. Coupling model of innovation

The national model has been introduced by the innovation theories of the XXI. century, as it is illustrated on Figure 3. This model suggests that not only research and markets generate demand for new products and services, but also the actors of national economy receive increasingly significant roles. It can be fundamentally stated that innovation is 
demand-oriented, by this is meant demands generated by buyers and producers. However, demand and conditions for innovation provided by the country also play significant roles. Preferential taxation, support, the promotion of entrepreneurship and mobility are priorities. (Figure 3.)

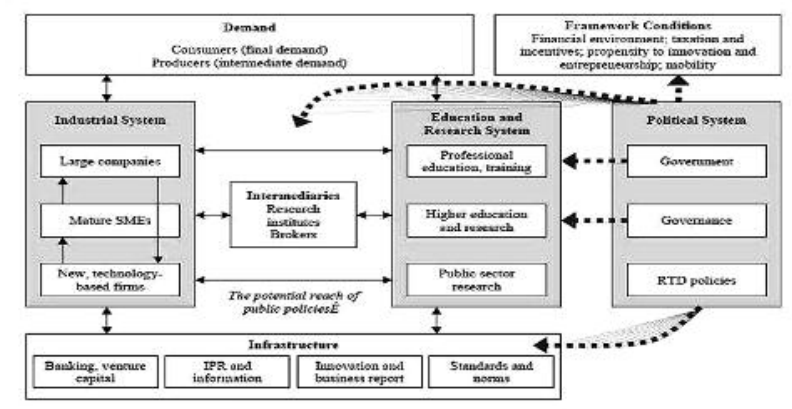

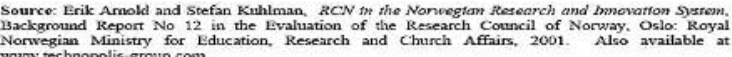

Figure 3. A National Innovation System model

Political regimes can indirectly promote innovation through their own infrastructure, and thus financial institutions, international investors, highly sophisticated and controlled information flow, e.g. the publication of open invitations to tenders, patents, innovations and their compliance with national and international standards can play key roles.

Politics can promote innovation not only through the instruments of its infrastructure, but directly or indirectly on governmental level. Its own research network, education system, especially in higher education induce the generation of demands for new products on one hand; on the other hand, they gear the assessment of market demands.

Practically, institutions of higher education and research represent an intermediate stage for industry and agriculture implementing innovation activities, for existing SMEs and large enterprises.

As a new element in our century, plenty of new companies are set up in order to exploit the research findings of innovation. These are called start-up or spin-off enterprises in daily practice.
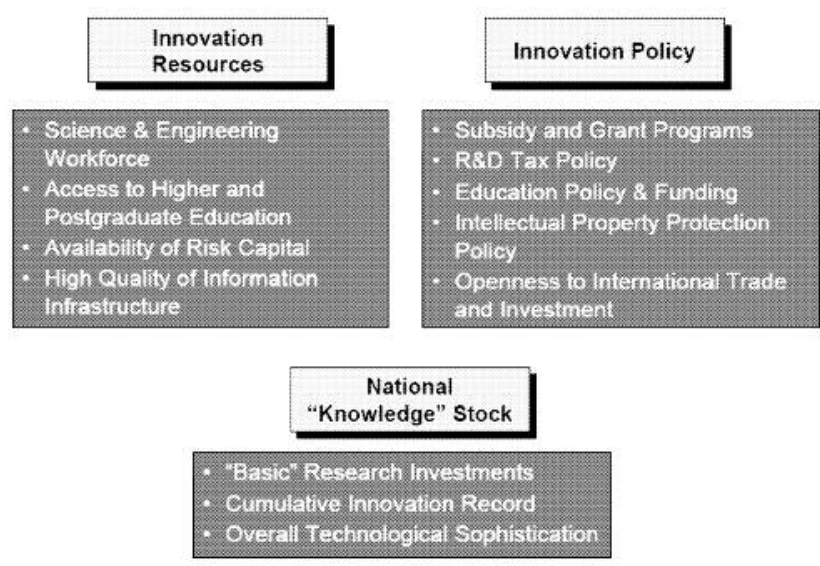

Figure 4. The Innovation Infrastructure Source: Scott Stern 2005
While innovation and knowledge can provide joint support merely for the creation of patents and innovations, infrastructure and organization forms can incite and support actual realization, implementation. Figure 4. shows the key elements of innovation infrastructure. The resources of innovation are based on fundamental and applied research resources, higher education and continuing training, primarily on invested capital and on the essentially significant structure of information worldwide.

Resources can be supported or inhibited by the innovation policy of current governments. These resources also include positive elements such as scholarship, research support, beneficial tax policy in relation to research development, state support for education, protection of patients and innovations stipulated by laws and also an open attitude by governments towards international "innovation trade" and investment. Innovation resources and innovation policy develop an international knowledge base jointly and it is measurable in basic research findings, cumulative innovation reports and the technological development level of a given nation.

Therefore, a knowledge based economy has four main pillars: 1. innovation, 2. education, 3. economic and organizational regime, 4. information infrastructure. Today innovation has accelerated inconceivably. New products and services, based on previous investments, have improved the knowledge base, especially in the area of chemistry, biology, space and nuclear research by an unprecedented, fast and extensive information and technological explosion. Naturally, various countries will improve and introduce innovation to different degrees.

In Hungary, innovation is based on 3 key pillars. Besides innovative enterprises, universities and research institutions play fundamental roles in this area. Our findings indicate that in EU countries and therefore in Hungary the process of innovation is to be concentrated in some larger regional centres. These knowledge centres shall also be competitive on the global market. In Hungary, besides 5-6 highlighted research universities which have already proved their competitiveness by international standards, the existence of 2-3 institutions per region for vocational and tertiary training is appropriate to present and disseminate the application of innovations. The relation of innovation and higher education is demonstrated in a survey by OECD, MSTI in 2006. Figure 5. shows the relation between Business Expenditure on R\&D (BERD) as a proportion of GDP and Higher Education Expenditure on R\&D (HERD) as a proportion of GDP.

Relation between Business Expenditure on R\&D (BERD) as a proportion of GDP and Higher Education Expenditure on R\&D (HERD) as a proportion of GDP.

Figure 5. clearly presents that developing countries, together with some ex-COMECON nations are on the bottom left part, also including a rich country such as Italy.

In the middle general part we can see EU and OECD countries, while countries of high level $R \& D$ are in the right upper section. Generally, a higher amount of money is coupled with higher level R\&D generated by industries. 


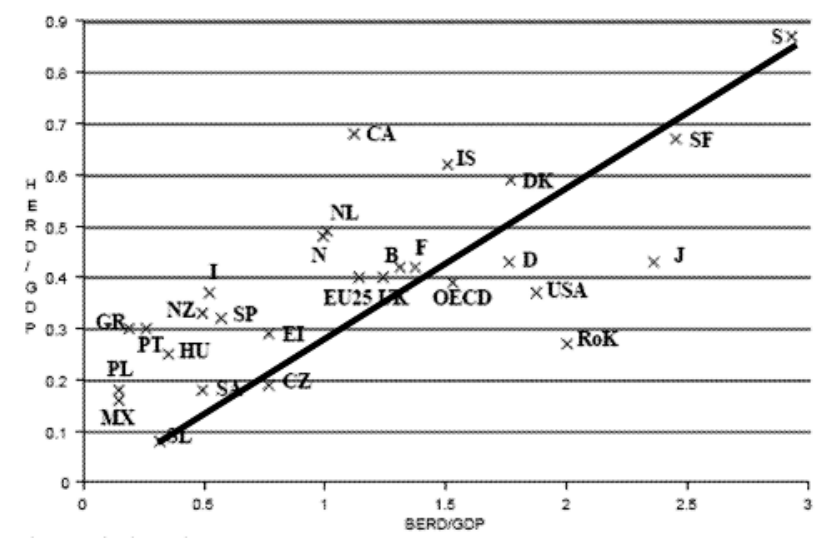

Figure 5. HERD/GDP vs BERD/GDP

Source: OECD, MSTI 2006

Figure 6 demonstrates the correlation between the economic wealth of nations and their "citation intensity". The graph shows the ratio of citations per unit (person) versus per capita GDP for the 31 nations. Wealth intensity is given in thousands of US dollars at 1995 purchasing-power parity.

The correlation is similar to data on Figure 5. Also, northern states, such as Finland, Sweden, Denmark and the Netherlands are highlighted in citation intensity while developing countries are placed in the bottom left third of the graph.

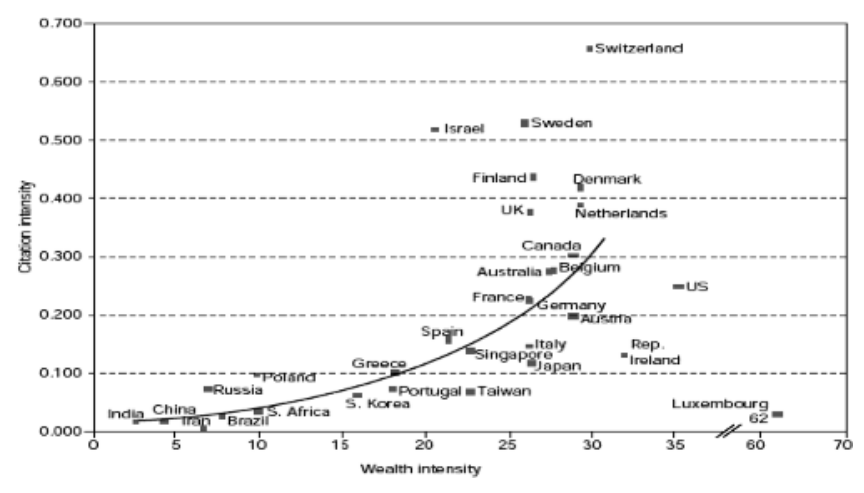

Figure 6. Link between citation and wealth intensities Sources: Thomson ISI, OECD and the World Bank

What does this correlation suggest? Innovation and knowledge base are successful if the related organization and infrastructure are available and countries support fundamental research and the dissemination of research findings with extensive resources in national or international cooperation.

\section{Solution on EU level}

The regulation of the European Parliament and the European Council states the significance of generating a new, community level initiative to complement national policies and to promote the integration of higher education, research and innovation in the European Union.

This new institution is the European Institute of Innovation and Technology; EIT. The organization aims to strengthen the innovation potentials of members states and the community and thus to contribute to sustainable European economic growth and competitiveness. All this is implemented by promoting and integrating high-quality higher education, research and innovation. Under this regulation, the task of the European Institute of Innovation and Technology is to cope with long-term challenges emerging in the EU, with especial regard to trans - and /or interdisciplinary areas. It also seeks to promote periodical dialogues with civil society. Furthermore, its key task is to place higher education, research and innovation activities in business context and to promote their application in industrial areas, to establish and to support starting enterprises and utilizing spin-off enterprises.

The European Institute of Innovation and Technology (EIT) prepares a 7-year innovation plan by 30 June 2011 at the latest and then one every 7 years and submits them to the Committee. The innovation plan identifies long term priority areas for the EIT and includes an evaluation on the social-economic impacts and potentials related to added value production. The establishment of the organization has been a significant milestone in the fifthfreedom rights, namely in the implementation of the free movement of knowledge. Its operation contributes to the boost of EU research and development, rectifies deficiencies of private financing and approximates the GDP proportion of 3\% stipulated by member states for R\&D.

EIT (European Institute of Innovation and Technology) is a worldwide, significant milestone in the dissemination of knowledge-based innovation among nations and is the infrastructure for the dissemination of innovation results.

\section{References}

Andrew Barnett (2009): "Innovation": re-labelling research or a shift in paradigm: the current debate in agricultural research for development? Andrew.Barnett@ thepolicypractice.com

Bjørn Asheim (2009): Towards a Comprehensive and Sustainable Human Capital Policy. 5th European Regional Economic Forum on 'Developing Human Capital and Managing Migration for more Competitive European Regions', Nova Gorica, Slovenia, 8-9 June, 2009

Diem Ho (2007): Research, Innovation and Knowledge Management: the ICT Factor. UNESCO July, 2007.

Erik Arnold (2007): Governing the Knowledge Infrastructure in an Innovation Systems World. www. idbdocs.iadb.org/wsdocs/ getdocument.asp $x$ ?docnum $=976013$

Fon van Oosterhout (2008): The Research + Innovation Program in Netherlands' development cooperation. 4th annual meeting of ASADI, London 4-5 November 2008.

Luc Soete (2009): Making innovation policies work in support of a recovery: key policy considerations. Informal OECD seminar on "Sustainability and the role of innovation policies in the current financial crisis", OECD, Paris, February 16th, 2009.

OECD (2009): Informal Seminar on Sustainability and the Role of Innovation Policies int he Current Financial Crisis. Paris, 16 February 2009. Summary and Conclusions.

Rajneesh Narula (2009): Multinational firms, globalization and innovation: policy implications for New Members States. Innovation for Competitiveness INCOM Prague / 22.1. - 23.1. 2009 
1 confess that the distinction I am making between amenity-augmenting policy (MFA) and place-based economic development policy is inconsistent with both US and European linguistic norms. US officialdom avoids the term MFA (perhaps for reasons rooted in international trade concerns - see Randall 2003 , 2007) but recognizes the policy-relevance of payments for ecosystem services, and programs to promote local, natural, and organic foods as well as more generic access to a safe and healthy food supply. The US has its framework of rural development programs, too, but views them as quite distinct from the above MFA-like programs. It seems that Europeans are more comfortable than I am, with including place-based regional economic development policies in their notion of MFA.

2 See also the Special Issue Comparing US and European Rural Development Policies, EuroChoices 7(1). 2008. http://www3.interscience.wiley.com/journal/ 119421781/issue 